This item was submitted to Loughborough's Research Repository by the author.

Items in Figshare are protected by copyright, with all rights reserved, unless otherwise indicated.

\title{
GOSIP in cyberspace: conceptualization and scale development for general online social interaction propensity
}

\section{PLEASE CITE THE PUBLISHED VERSION}

http://dx.doi.org/10.1016/j.intmar.2013.09.003

\section{PUBLISHER}

(c) Direct Marketing Educational Foundation, Inc. Published by Elsevier.

\section{VERSION}

AM (Accepted Manuscript)

\section{PUBLISHER STATEMENT}

This work is made available according to the conditions of the Creative Commons Attribution-NonCommercialNoDerivatives 4.0 International (CC BY-NC-ND 4.0) licence. Full details of this licence are available at: https://creativecommons.org/licenses/by-nc-nd/4.0/

\section{LICENCE}

CC BY-NC-ND 4.0

\section{REPOSITORY RECORD}

Blazevic, Vera, Caroline Wiertz, June Cotte, Ko de Ruyter, and Debbie Keeling. 2013. "GOSIP in Cyberspace: Conceptualization and Scale Development for General Online Social Interaction Propensity”. Loughborough University. https://hdl.handle.net/2134/17117. 
GOSIP in Cyberspace:

Conceptualization and Scale Development for General Online Social Interaction Propensity

VERA BLAZEVIC*

CAROLINE WIERTZ

JUNE COTTE

KO DE RUYTER

DEBBIE ISOBEL KEELING 
* Corresponding author. Vera Blazevic is Assistant Professor at Radboud University Nijmegen, Institute for Management Research, Department of Marketing, P.O. Box 9108, 6500 HK Nijmegen, The Netherlands and Visiting Professor at RWTH Aachen University, School of Business and Economics, Technology and Innovation Management Group, Kackertstr. 7, 52072 Aachen, Germany,Email:v.blazevic@fm.ru.nl, Phone: +49 (0)241809 3581/Fax: +49 (0)241809 2367.

Caroline Wiertz is Reader in Marketing at Cass Business School, City University London, 106 Bunhill Row, London, EC1Y 8TZ, United Kingdom. Email: c.wiertz@city.ac.uk, Phone: +44 (0)20 7040 5183/Fax: +44 (0)20 70408328.

June Cotte is R.A. Barford Professor of Marketing at Ivey Business School, Western University,, 1151 Richmond Street, London, Ontario, N6A 3K7, Canada. Email:jcotte@ivey.ca, Phone: 519 661 3224/Fax: 5196613959.

Ko de Ruyter is Professor of Interactive Marketing at the University of Maastricht, Faculty of Economics and Business Administration, Marketing Department, P.O. Box 616, 6200 MD Maastricht, The Netherlands, Email: k.deruyter@maastrichtuniversity.nl, Phone: +31 (0)43 388 3839/Fax: +31 (0)433884918.

Debbie Isobel Keeling is Assistant Professor of Marketing at Loughborough University, School of Business and Economics, Ashby Road, LE11 3TU, United Kingdom, E-mail:

D.I.Keeling@lboro.ac.uk, Phone: +44(0)1509 223117 


\begin{abstract}
The interactive nature of the Internet has boosted online communication for both social and business purposes. However, individual consumers differ in their predisposition to interact online with others. Whereas an impressive stream of research has investigated media interactivity, the existence of individual differences in the use of different online media, that is, differences in general online social interaction propensity, has so far received less research attention. An individual's predisposition to interact online affects many important consumer behaviors, such as online engagement and participation. Thus, in this paper, we propose and conceptualize general online social interaction propensity as a trait-based individual difference that captures the differences between consumers in their predisposition to interact with others in an online environment. Based on eight studies, we develop and validate a scale for measuring general online social interaction propensity and demonstrate its usefulness in understanding diversity in levels of engagement and in predicting online interaction behaviors.
\end{abstract}

Keywords: scale development, general online social interaction propensity, individual difference, social media 


\section{INTRODUCTION}

The global penetration of Internet technologies has profoundly changed the scope and boundaries of social and economic interactions. Currently, an estimated 2.4 billion users regularly access the Internet to find information, connect with others, entertain themselves and complete transactions, unconstrained by distances in time and space (IWS 2012). About 90\% of these Internet users access social media, such as blogs (e.g., Huffington Post), online video sharing sites (e.g., YouTube), online social networks (e.g., Facebook, MySpace, etc.), microblogging sites (e.g., Twitter), brand communities (e.g., Harley Davidson) and peer support communities (e.g., Microsoft support forums). These social media applications allow consumers to consume, create and exchange content, and organizations exploit interactive social media opportunities to engage consumers more effectively. Engaged consumers feel a stronger connection to the brand and/or firm (Calder and Malthouse 2008), are more likely to support viral marketing campaigns (Brodie et al. 2011), to participate in firms' brand and fan communities (Algesheimer et al. 2005) and to provide feedback to firms for innovation (Kumar et al. 2010). At the same time, however, the distribution of participants in online environments is certainly skewed. There are some consumers who predominantly use social media sparingly, and avoid active engagement in social platforms (Daniels et al. 2003).Despite these notable variations in people's online behavior, research on individual differences with regards to online interaction behavior is scarce (Wiertz and de Ruyter 2007, Tremayne 2005).

The core modus operandus of social media platforms is interaction, underpinning levels of engagement. However, while the interactive functions of Web sites can be used to facilitate customer interactions (e.g., van Noort et al. 2012); crucially, not all consumers interact equally

when given the opportunity (Liu and Shrum 2002). There have been several literature reviews on web site interactivity (Johnson et al. 2006, Liu and Shrum 2002, McMillan and Hwang 2002, 
Song and Zinkhan 2008), yet interactivity research has neglected the interactivity of the consumer.Consumers may differ in their dispositions to approach or avoid interaction online and socompany strategies could be operating on a flawed assumption; a push strategy of offering interaction opportunities to all could be limited in potential and may not necessarily lead to increased interaction. Previous research that has focused on the interactive properties of online environments has yielded an equivocal picture at best when it comes to accounting for consumer attitudes and behavior (Ariely 2000). Researchers have also noted that when interaction functionality is imposed on consumers without taking into account individual preferences, it can result in negative sentiment towards a particular company and to online interaction in general (Daniels et al. 2003). But why?

It appears there is a difference between consumption (lurking/observing) and contribution (posting/generating) activities online (Schlosser, 2005). Individuals who actively contribute to online communication (for example, those who post a message online) are relatively few, compared to the overwhelming number of passive lurkers, who only read and observe contributions and discussions of others (Cothrel and Williams 1999; Kozinets 1999; Preece, Nonnecke, and Blair 2004). We know that posters and lurkers differ at an individual level in the way that they interpret and process information acquired online (Schlosser 2005). What we lack, however, is an understanding of the reasons why some individuals are more inclined to post while others are more inclined to lurk, despite both groups having similar access ability and sharing similar motivations for consuming online information.

We argue that the extent and nature of a wide variety of online consumer behaviors, such as blogger communication strategies (Kozinets et al., 2010), the use of personal web space for self-presentation (Schau and Gilly 2003), the ability to elicit self-disclosure through computermediated channels (Moon 2000) and the formation of collective intentions in online communities 
(Bagozzi 2000) are underpinned by 'general online social interaction propensity,' defined as an individual's trait-based predisposition to participate in online interactions (Wiertz and de Ruyter 2007). While interactivity refers to an attribute of an online environment, general online social interaction propensity is a global individual difference characteristic that underlies a consumer's preferences and interaction behavior across online contexts,the difference in people's proneness to interact online. We consider this a so-called 'surface-level' trait (e.g., Mowen and Sujan 2005) that is specific to consumers' inclinations with regard to online contexts. We develop a measure for gauging the differential propensity to interact online and argue that this is a different construct than others, such as willingness to communicate offline; we offer evidence that it is important to allow marketers to accurately understand and measure this new construct.

This paper is structured as follows. We begin by conceptualizing and theoretically delineating general online social interaction propensity as a trait-based individual difference. We develop and empirically validate a pragmatic scale for its measurement. Finally, we explore consumer heterogeneity in general online social interaction propensity through its impact on engagement and online behavior across different social media platforms. We conclude with a discussion of the implications of our work for both interactive marketing researchers and practitioners.

\section{INTERACTIVITY AND ONLINE INTERACTIONS}

The rise of social media application popularityis due largely to interactive communication. Interactivity is often discussed as either personal interactivity (i.e., interactivity through the medium) or machine interactivity (i.e., interactivity with the medium) (Hoffman and Novak 1996). Whereas the former concentrates on the user-to-user interaction mediated via 
technology, the latter focuses on the user-to-technology interaction. Research on interactivity mainly focuses on web site interactivity and its effects (van Noort et al. 2012, see the extensive literature reviews by Johnson et al. 2006, Liu and Shrum 2002, McMillan and Hwang 2002, and Song and Zinkhan 2008). Interactivity is usually defined as "the degree to which two or more communication parties can act on each other, on the communication medium, and on the messages and the degree to which such influences are synchronized” (Liu and Shrum 2002, p. 54). This definition integrates both approaches to interactivity by incorporating user-to-user and user-to-machine interactions. Other researchers follow Steuer's (1992) telepresence theory, where the important dimension of interactivity is its malleability of a medium's form and content (Tremayne 2005). More complexity has recently been added by differentiating between: 1) a structuralist view, where interactivity isthe response to the structural properties of the online medium, and 2) a perceptional view, which considers perceived interactivity as the experience of a user during his interaction with a Web site (Mollen and Wilson 2010). Despite this definitional complexity and lack of consensus, it is clear that interactivity is not only a characteristic of the technology, but includes human-message interactions. Surprisingly, interactivity researchers have neglected the idea that interactivity might be a characteristic of consumers. We argue that participating in online interactions does not only depend on the interaction opportunities afforded by a medium, but also on a person's predisposition to act on these interaction opportunities (Wiertz and de Ruyter 2007).

In our view, interactivity is a trait characteristic of the consumer. The consumer ultimately decides to communicate online, and the medium simply facilitates that decision (Schumann, Artis, and Rivera 2001).

Communication and psychology researchershave recognized for decades that individuals have different predispositions to communicate with others in face-to-face situations (Mortensen, 
Amston, and Lustig 1977). Variability in communication behavior is clearly attributed to traitbased individual differences, most notably willingness-to-communicate (McCroskey and Richmond 1990). Willingness-to-communicate is defined as the likelihood of initiating communication, especially talking, in different communication contexts (small or large audiences) and to different communication receivers (strangers versus acquaintances).

Conversely, another stream of research has focused on interaction avoidance via communication apprehension (McCroskey 1984a), and reticence (Phillips 1984). Whereas willingness-to-communicate indicates when an individual is willing to interact, apprehension and reticence reflect an individual's interaction ability and lower levels of communication efficacy. Reticent people tend to believe that they gain more by avoiding interacting with others (Phillips 1984). Despite intricate nuances, the central tenet in this stream of research is that individuals vary as to what degree they will interact with other people. However, while there is evidence that willingness-to-communicate successfully predicts the talkativeness of individuals in the offline world (e.g., McCroskey and Richmond 1990, McCroskey 1992), we argue and demonstratethat it does notadequately capture differences in online communication behavior. Online computermediated communication differs profoundly from offline face-to-face communication (Flaherty, Pearce, and Rubin 1998; McKenna and Bargh 2000; Sproull and Kiesler 1986; Valacich et al. 1993). These important differences, outlined below, preclude a simple borrowing of scales when measuring online communication.

There areimportant differences in media richness and reach, where online communication channels tend to have lower richness, but often higher reach, than offline communication (Daft and Lengel 1986). Offline communication is perceived as rich (as opposed to lean online communication) due to its availability of instant feedback, capacity to transmit multiple cues (including non-verbal cues), use of natural language, and the personal focus of the channel (Daft 
and Lengel 1986). Online interactions have a wider geographic and temporal reach due to the truly global nature of the Internet (McKenna and Bargh 2000).

There are also differences between online and offline communication that are determined by the nature of the context. In online communication, partners may be strangers. This is often the case in online communities, topic groups in online social networks, Internet discussion boards (e.g., comments on YouTube), as well as chat rooms and newsgroups dedicated to a specific area of interest. Due to the low familiarity between interaction partners, the level of disclosure online might be different than in offline communication situations (Mehrabian 1980). Finally, people can choose to remain anonymous online, often assuming nicknames or complete online personae. This high level of anonymity can have both positive consequences (more liberated behavior) and negative consequences (more aggressive behavior) (Culnan and Markus 1987; Moon 2000; Schau and Gilly 2003).

Based on these differences, we argue that online and offline communication media are not functional alternatives (Flaherty et al. 1998). Thus, it is not suitable to simply transfer priorunderstanding, using concepts developed for offline behaviors (such as the offline willingness-to-communicate trait), and apply it to an online context. Rather, it is necessary to develop a novel online counterpart to the offline concept of willingness-to-communicate.We strongly believe that some consumerswho may be willing to interact online may not be willing to communicate to the same extent offline, and vice versa.

\section{GENERAL ONLINE SOCIAL INTERACTION PROPENSITY (GOSIP)}

We define general online social interaction propensity (hereafter GOSIP) as a trait-based individual difference in the predisposition to enter into online discussions. This definition 
presumes that consumers are active participants in the online marketplace, and that attention should be paid to their interaction preferences. As we argued, prior research on the interactive capability of the different communication media should be complemented by a focus on individual interaction preferences. GOSIP is an individual difference that explains the potential level at which one person will participate in an online interaction and another person will not, givensimilaraccess and motivational circumstances. While trait-based differences are expected to vary between individuals, they should be rather stable across situations (Zuroff 1986). This consistency across situations, however, does not mean that individuals will always behave exactly the same way regardless of context (Shoda, Mischel, and Wright 1994). For example, topic salience might prevail over low interaction propensity. In case of an emergency, even a person who is completely disinclined to interact online might overcome this disinclination if the online communication activity promises to result in urgently needed help. Thus, we follow an interactionist perspective in arguing that general online social interaction propensity is a traitbased individual difference that is relatively consistent across contexts, yet directly impacted by those contexts. This perspective is in line with recent research in social psychology, which has shown that interactional effects of personality traits and situations are universal manifestations of personality (Kammrath, Mendoza-Denton, and Mischel 2005).

\section{GOSIP and Engagement}

The major contribution of developing the GOSIP concept is its explanatory power for consumer engagement and online interaction behaviors. Consumer engagement has been conceptualized as the employment and expression of a preferred self in task and social behaviors; it is considered a motivational construct (Kahn 1990; Salanova, Agut, and Peiró 2005). Robinson et al. (2004) report considerable variation in empirical evidence as to what drives engagement. 
As the prevalent conceptualization of engagement centers around the expression of the self, researchers have started to chart whether certain dispositional differences can be associated with the likelihood to be engaged in interactive activities. These differences should persist over time and across a number of interactive contexts. An emerging body of empirical evidence links engagement to individual traitssuch as having a proactive and autotelic personality, and being conscientious (Macey and Schneider, 2008a). Furthermore, Langelaan et al. (2006) have expanded the list of predictors of engagement by identifying that individuals high in extraversion are most likely to become engaged and involved in (work) tasks and socialization. A recent study by Salgueira et al. (2012) has added openness to experience as a personality trait that is positively associated with engagement levels. An underlying communality, therefore,uniting thedispositional drivers of engagement is what could bebroadly termed an approachorientation (Smith et al. 2009).

In our conceptualization, GOSIP is an important driver of engagement; we assume that people are ready to consider online channels to engage in interaction with others. This is corroborated by research on co-creation that has established the willingness to enter into a dialogue as a precursor to customer engagement (Ballantyne and Varey, 2006). Furthermore, it has been suggested that the interaction proneness of a core of online community members is central to the social configuration of value in brand communities (Muñiz and O’Guinn, 2001; Schau, Muñiz and Arnould, 2009). Finally, Libai et al. (2010) argue that customers who interact with others in an online environment are a valuable source of information, and have a positive impact on experience sharing,which in turn results in greater participation levels and perceived value. Therefore, we propose that general online social interaction propensity is positively associated with engagement and the level and nature of online interaction behaviors. 
The remainder of this paper is divided into three sections. First,we describe the process of conceptual refinement and scale development. We then go on to explore the relationships between GOSIP, engagement, and online behaviors. Finally, we discuss the main implications for theory and practice.

\section{GOSIP CONCEPTUAL REFINEMENT AND SCALE DEVELOPMENT}

We began by conducting two qualitative studies focusing on conceptual refinement and item generation, and then continued with three quantitative studies focusing on scale refinement in terms of reliability and validity. In Study 1, we explore the general online social interaction propensity concept and generate initial scale items by means of two in-depth case studies and a literature review. In Study 2, interviews with academic and business experts help to select and refine the initial scale items. Study $3(n=287)$ tests the unidimensionality and reliability of the 30 items that were retained after Study 2. Study $4(n=320)$ evaluates discriminant validity by assessing the GOSIP scale, together with conceptually close constructs and social desirability bias. Study $5(n=195)$ establishes nomological validity through demonstrating the explanatory power of general online social interaction propensity for consumer behavior in an online community setting.

\section{Study 1 - Refining the GOSIP Concept}

We conducted two case studies, one at a leading global computer services company and the other at a global provider of job exchange services. These companies have a wide variety of online service channels offering different degrees of interaction opportunities. In the first company, three channels with low, medium and high interaction capability (an online problem 
solving tool, a customer feedback service, an online technical support forum) were selected and studied. We interviewed 27 managers, 9 technical customer assistance specialists and 7 customers operating within these channels. In the second company, we interviewed 4 managers and 4 customers, who were all involved with the online platform of this company. In the online community members can search for jobs, seek and provide advice for job-related issues, and connect to like-minded members for information exchange.

A thematic content analysis was applied to the data using the process suggested by Spiggle (1994). Specifically, we categorized case study data (i.e., interview transcripts, observation notes, internal documentation, community discussions and posts) into emergent content themes. We then compared the differences and similarities across incidents and with relevant literature. After we dimensionalized the data by identifying the attributes and characteristics of the themes, we moved to integration. The observation that customers differ in their propensity to interact online was clear at this step. We downloaded additional interaction events (e.g., posts and threads) from the original case study source channels to identify counterexamples and challenge our interpretations. For each electronic interaction channel, we prepared a detailed report of our findings, which we sent to informants as a form of member checking. Thus, we validate our insights through prolonged engagement with the identified channels, with comprehensive, descriptively rich data from various sources, and through verification of our results with informants.

The results from these qualitative studies confirm that customers are indeed very different in their online behavior and appear to have a general predisposition to contribute or not to online interactions. This predisposition is readily recognized and can be articulated by our informants. For example, the operational manager of an online discussion forum in computer services explained that: 
"The members of the community are just different; some are more verbal and enjoy talking about it [their problems]. Some prefer to read only and don't like to communicate with others." (computer services manager)

The customer members of this forum agreed with the manager’s observations. One customer from the computer services company pointed out:

"I am a very active member, I enjoy talking to all kinds of people online, but I am sure that there are many other people who just like to read our conversations.”

Furthermore, another customer, this time from the job exchange service company, who described himself as a "lurker" confessed the following:

"I don't really participate actively - I know I should but if I can find the information I need without asking, I would always prefer that.”

Three common themes emerged from the interviews that characterized GOSIP (please see figure 1): the level of interaction, social preferences and enjoyment in interaction. Level of interaction describes the degree of interactive behavior ranging from lurking to actively contributing content. For example, an engineer of the computer services company explained:

"Customers inherently differ in their behavior in our service channels. Some only read the manuals while others actively seek advice or even like to help other customers”.

Social preferences describe the degree of desiring a sense of belonging originating in the online interaction. A customer of the job exchange service company noted:

“In my current situation [i.e., being unemployed], my normal friends cannot really understand how I feel. The other members [of that Web site] are in the same situation; I feel much more connected to them”.

Enjoyment in interaction describes how much a person likes the interactive exchange with other persons online. A customer of the computer services company pointed out: 
"It is just so much fun to talk to the other people."

In contrast, another customer of the same service told us:

"I do not like all that social chatting. I just want to have my problem solved and then I leave again”.

\section{INSERT FIGURE 1 HERE}

\section{Study 2 - Item Development}

Based on the three emergent themes from study 1, together with interviews with 14 business managers and 8 virtual community members, and the aforementioned literature review on interactivity and individual differences in engaging in communication, we developed an initial item pool of 54 items to capture GOSIP.

The content validity of the items was assessed using five academic experts and three business managers. First, they were given the definition of GOSIP, a related explanation, some representative interview quotes and an example item. The judges were then asked to rate each statement as clearly representative, somewhat representative and not representative of GOSIP. Items that were rated clearly representative by at least five judges, and somewhat representative by the remaining judges, were retained. This process eliminated 24 items, leaving 30 items. The remaining set of 30 items reflected interaction, social and enjoyment preferences for various online channels (chat, discussion forums, blogs) as well as overall online interaction, social and enjoyment preferences. For example, interacting with others online is not important to me or I am someone who thoroughly enjoys talking to other people online. 


\section{Study 3 - Item Refinement}

As a next step, we collected data on these 30 items with an online questionnaire froma student sample of undergraduate business students from a midsized university in the Netherlands ( $\mathrm{n}=287 ; 128$ females and 159 males). The questionnaire included several examples of online sites with interaction functionality (e.g., an online community) and respondents were requested to carefully look at these sites before completing the GOSIP items. We deemed students as appropriate respondents in this context as GOSIP is an individual difference that we assume applies to everyone.

Data were randomly divided into two halves. The first half was subjected to exploratory factor analysis (EFA), resulting in a six factor solution. Based on an inspection of the relative eigenvalues, we retained the first factor, consisting of eight items with loadings exceeding .60 (Steenkamp and van Trijp 1991). Crucially, the three themes that had emerged from the qualitative study (level of interaction, social preferences and enjoyment) were equally represented on the first factor. Thus, from our EFA we concluded that GOSIP could be measured as a unidimensional factor. For this factor,a composite reliability (CR) of .93 and an average variance extracted (AVE) of .62 indicated high internal consistency. With regard to the remaining items, the second factor had only two items, loading above .60, which concentrated on online chats and hence were deemed too specific. The third factor had one item loading above .60 considering feelings of insecurity online. All other items did not load above .60 on any of the factors.

Our conclusions were tested in the next analysis phase. The second, randomly selected, half of the data was subjected to confirmatory factor analysis (CFA) using EQS version 6.1. The one-factor structure was replicated and fit the data well (McDonald and Ho 2002) (Chi square $(d f)=30.24(20), N N F I=.97, C F I=.98, G F I=.93, R M S E A=.06)$, thereby indicating 
unidimensionality (Steenkamp and van Trijp 1991). Composite reliability for the scale in the second half of the data was .95 and AVE was .69. All item loadings were significant (all loadings $>$.62, min. $t$-value $=4.2$ ), indicating convergent validity. Table 1 displays the final eight items of the GOSIP scale, along with the highlights of the EFA and CFA analyses.

\section{INSERT TABLE 1 HERE}

\section{Study 4 - Discriminant Validity}

The fourth study evaluated discriminant validity by examining the GOSIP scale together with conceptually close constructs: willingness-to-communicate (offline), involvement with online communication and extraversion. Willingness-to-communicate (WtC) is a trait-like disposition to engage in or avoid communication in face-to-face situations (Zakahi and McCroskey 1989). WtC should be different from GOSIP due to the distinct differences between online and face-to-face communication. People might be very willing to communicate in face-toface situations, but disinclined to engage in online interactions, and vice versa.

Involvement with online communication is based on Zaichkowsky’s context-free revised personal involvement inventory (Zaichkowsky 1994). It is defined as a motivational state, in which online communication as the stimulus object is personally relevant to a person. We specifically focused the context on online communication to be conceptually as close as possible, and thus we apply a more stringent test of discriminant validity. Personal involvement with online communication should be different from a behavioral orientation to engage in online interactions, as involvement is a state rather than a trait and varies easily in different situations. 
Extraversion is one of the Big Five personality dimensions, originally developed by Hans Eysenck. Extraverted individuals are characterized as sociable, gregarious, assertive, talkative, and active (LePine and Van Dyne 2001). Hence, in face-to-face encounters, extraverts tend to interact and communicate more than introverted persons. The effect of extraversion on interactions over the Internet is less clear. Previous research has been inconclusive. For instance, Peris et al. (2002) expected extraverts to use online interaction methods to find new acquaintances, given their high level of sociability, and because extraverts seem to know best how to interact with other people. However, they did not find any differences in chat behavior based on extraversion. In contrast, Amichai-Hamburger, Wainapel and Fox (2002) argue that introverts engage more in online interactive services as they are intrigued by the Internet features of anonymity, rigid control of information, and the neglect of physical appearance. Hence, introverts can overcome their offline difficulties in forming social contacts.

In addition to these conceptually close constructs, we also tested the influence of social desirability bias (Crowne and Marlowe 1960) to assess whether our scale truly reflects GOSIP rather than the tendency to self-report in a socially desirable way (Tian, Bearden, and Hunter 2001).

In this study we collected data from a student sample, obtaining 320 responses (125 females and 195 males, average age of 20). In the WtC scale respondents were presented with 14 different communication situations and had to indicate a percentage (0 to 100 ) for the likelihood that they would communicate in each situation (see McCroskey and Richmond 1990). Involvement with online communication was measured with 9 items using a seven-point semantic differential scale based on the revised personal involvement inventory (Zaichkowsky 1994). Extraversion was measured with 8 items of a seven-point Likert scale based on Comrey, Noller, and Law (1988). We assessed discriminant validity between GOSIP and the three above- 
mentioned conceptually close constructs with a series of EQS estimations, where we constrained and freed the phi coefficient (Anderson and Gerbing 1988) ${ }^{1}$. Thereafter, we performed chi-square difference tests. In all cases, the free coefficient model was superior to the constrained one (GOSIP-WtC: $\Delta \chi^{2}(1)=94.90, p<.001$; GOSIP-iwoc: $\Delta \chi^{2}(1)=51.45, p<.001$; GOSIP-ev: $\Delta \chi^{2}(1)=$ 46.00, $p<.001$ ), demonstrating discriminant validity. Furthermore, the square root of GOSIP's AVE (AVE=0.58, SQRT(AVE)=0.762) is higher than each correlation of GOSIP with the other three constructs (Fornell and Larcker 1981). Also, each correlation of GOSIP with the other constructs was less than 1 by an amount greater than twice its respective standard error (Bagozzi and Warshaw 1990).

However, we also wanted to see how WtC, involvement with online communication, and extraversion, relates to GOSIP. The correlations based on the initial factor analyses (with maximum likelihood estimates) are shown in Table 2. Our results show that consistent with previous research, extraversion is positively related to offline communication (willingness-tocommunicate, WtC). But importantly, in our online setting, we find that extraversion has no relationship to general online social interaction propensity. We can also see that the willingnessto-communicate offline is not related to GOSIP. There is, however, a significant correlation between GOSIP and the involvement with online communication, whereas WtC (offline) is not related to involvement. It theoretically makes sense that people having a high propensity to interact online also have higher feelings of involvement in online communication. This supports our earlier proposition that there is a need for an online specific concept for interaction propensity; in online contexts it is not sufficient to borrow from offline concepts.

\footnotetext{
${ }^{1}$ The CFA without constraints that serves as comparison has the following fit: Chi square $(d f)=1586.21(696)$, $N N F I=.82, C F I=.84, G F I=.78 .$, RMSEA $=.06$.
} 


\section{INSERT TABLE 2 HERE}

We also assessed the impact of the Marlowe-Crowne social desirability index (MCSDI) on GOSIP. Thus, we performed a multigroup analysis with EQS by first splitting our file into two groups. The first group contains respondents that scored low on MCSDI, while the second group includes respondents scoring high on MCSDI. Thereafter, we established measurement invariance by constraining first the factor loadings to be equal across the two groups, second the factor variance and third the error variances. We used Lagrange Multiplier tests to investigate whether any constraints had to be released. No constraint had to be released, as indicated by both univariate as well as multivariate test statistics. The constrained model shows a good fit (McDonald and Ho 2002) $($ Chi square $(d f)=91.69(55), N N F I=.97, C F I=.98, R M S E A=.065)$. Hence, the two groups show measurement invariance and thus we conclude that MCSDI has no impact on our GOSIP measurement instrument, boding well for potential uses of our scale in future research.

\section{Study 5 - Nomological Validity}

The purpose of Study 5 was to establish nomological validity by demonstrating the explanatory benefit of GOSIP to understanding online consumer behavior, while also replicating our tests of discriminant validity in a non-student context. As our research setting, we chose an online technical support community in which very active members as well as heavy lurkers (i.e., members who only read and never actively interact with others) participated. ${ }^{2}$ Our data were

\footnotetext{
${ }^{2}$ The community publishes statistics on the activity behavior of all registered participants. From these statistics, we could ensure that there are large differences in their level of participation. Also, the community provides a reputation
} 
collected by means of an online questionnaire that was advertised and linked to the community's main starting page. On this starting page, the community has a specific box where news and special links are promoted. Furthermore, we posted a thread in the 23 most active discussion forums of that same community explaining the rationale of the study and inviting the members to participate. We offered participants an extrinsic incentive to participate by raffling Amazon vouchers. In addition, we provided an intrinsic incentive by promising to publish the results. By providing an extrinsic as well as intrinsic incentive we wanted to stimulate light as well heavy users to participate in our study.

In total, 195 questionnaires were completed. The majority of the respondents were from the US, but in total people from 25 countries participated. The main age category was the one between 25 and 45 years (64.4\%). Furthermore, participants came from a wide variety of industries, such as agriculture, pharmaceutical, telecommunication, with IT being the major category (45.2 \%). On average, participants are in the community for five and a half hours per week, but $13 \%$ spent more than 10 hours per week participating in the community. Seventy percent of the respondents stated that more than half of their problems are solved in the community. It is important to note that the results show a highstandard deviation with regard to our GOSIP construct (mean: 4.68, std. dev.: 1.32). Furthermore, our sample includes a wide variety of members, including active members as well as lurkers, and experienced as well as novice community members.

system where members can provide and collect points for the helpfulness of the answers. In total, there are six experience levels (depending on the number of accumulated points). In our sample, $57.2 \%$ had not yet accumulated enough points for the first experience level, $6.4 \%$ were from experience level $1,9.2 \%$ from level 2, $9.8 \%$ from level 3, $11 \%$ from level 4, 4.6\% from level 5, and $1.7 \%$ from level 6 . Hence, we have captured a wide variety of non-active and active members. 
In addition to GOSIP, self-reported information posting behavior, social interaction behavior and helping behavior were measured. Information posting behavior was measured with 3 items of a seven-point Likert scale adapted from Ridings, Gefen and Arinze (2002), focusing on the provision of information and advice to other members of the virtual community. The construct had a composite reliability of .97. The measure of social interaction behavior was adapted from Reynolds and Beatty (1999) and asked with 5 items about the communication with other members on social aspects. The construct had a composite reliability of .97. Helping behavior was assessed with 4 items of a seven-point Likert scale adapted from Podsakoff, Ahearne and McKenzie (1997) including the respondents' likelihood and encouragement to help each other. The construct had a composite reliability of .94.

Discriminant validity was again assessed with the help of chi-square difference tests, after freeing and constraining the phi coefficients (Anderson and Gerbing 1988). In all three tests, the free coefficient model was superior to the constrained one indicating discriminant validity (GOSIP-ipb: $\Delta \chi^{2}(1)=16.07, p<.001$; GOSIP-sib: $\Delta \chi^{2}(1)=30.92, p<.001 ;$ GOSIP-hb: $\Delta \chi^{2}(1)=$ 16.07, $p<.001)^{3}$.

Nomological validity is established when a measure empirically reflects results that are consistent with conceptual expectations (Cronbach and Meehl 1955); in this case we examined the degree to which GOSIP explains information posting behavior, social interaction behavior and helping behavior. We expect consumers who have a high general propensity to engage in online social interactions (GOSIP) to be more likely to provide information and advice to other consumers online. Furthermore, these consumers will also enjoy online social interaction more

\footnotetext{
${ }^{3}$ The CFA without constraints that serves as comparison has the following fit: Chi square $(d f)=476.86(164)$, NNFI $=.93, C F I=.94, G F I=.81, R M S E A=.07$.
} 
than consumers who score low on GOSIP. Finally, consumers high in GOSIP will help others online more often, as they like the online interaction.

We tested the predictive impact of GOSIP on information posting behavior, helping behavior and social interaction behavior with structural equation modeling using EQS. The results provided in Table 3 show that general online social interaction propensity is indeed a strong predictor of all three types of behavior.

INSERT TABLE 3 HERE

\section{GOSIP'S IMPACT: ENGAGEMENT AND ONLINE BEHAVIOURS}

In this section, we describe three quantitative studies that explore the relationship of GOSIP to engagement and online behaviors within various contexts. Study 6 ( $n=291)$ principally focuses on the relationship between engagement and GOSIP in three different contexts (online community, online review and video sharing), while extending the discriminant validity of the GOSIP. In Study 7 and 8, we collect data from an online technical support community ( $n=162)$ and an online movie review community $(n=40)$ and relate GOSIP to objective, online behavioral data to assess whether our scale predicts actual consumer behavior.

\section{Study 6}


In Study 6, we verified the validity and generalizability of the GOSIP scale within three different contexts and then established the nature of the proposed relationship between GOSIP and engagement.

An engagement measure was developed specifically for use in this study based on parts (“participation and socializing” and “community”) of a scale by Calder et al. (2009). There is debate in the literature regarding the conceptual definition of engagement. While it is not within the scope of this paper to present a comprehensive review of this debate, there is consensus within the literature that engagement is multifaceted. The two most commonly applied facets relate to ‘social connectedness' and ‘task or behavioral engagement' (e.g., Salanova, Agut, and Peiró 2005; Calder and Malthouse 2008). Social connectedness represents the relational aspects of engagement between two parties, including level of interest and two way impacts. Task or behavioral engagement represents the outward manifestations of engagement, including effort to maintain or contribute to the relationship and level of advocacy and passion (PeopleMetrics 2009). Our engagement measure captures these two dimensions with items measuring two distinct factors (social engagement (3 items) and effort engagement (6 items). Engagement items were measured on a 7-point Likert-type scale with Cronbach’s alpha 0.807 for social engagement and 0.880 for effort engagement. Building on our earlier general propositions, we argue that those higher in GOSIP will develop a deeper social connectedness and make more effort to retain and contribute to those relationships as compared to those low in GOSIP.

Firstly, the discriminant validity of GOSIP was tested across three contexts; a social networking context (we prompted with examples of Facebook or Twitter), an online review context (our examples were Amazon or TripAdvisor) and a video sharing context (e.g., YouTube or Vimeo). We administered an online survey to Amazon Mechanical Turk (MTurk) subscribers that assessed their WtC, extraversion, and GOSIP measures plus the two new engagement scales 
(the wording of which was necessarily matched to the three contexts). As is common with MTurk, incentives per survey completion are low (in this case 10 cents). The resultant sample size was 291 (41\% male). As one might expect from a sample recruited from MTurk, these were regular online users, with $98.3 \%$ having used the internet for more than threeyears,and $80 \%$ spending more than 10 hours per week online. About an equal percentage of respondents went online for information or for entertainment (39\% and 41\%, respectively), with far less (18\%) stating they used it to communicate or to buy products or services (2\%).

For all three contexts a CFA was performed using AMOS 20 (with ML estimation). The model statistics for the three conditions suggest an acceptable fit for the five factor model (see table 5); with the social networking and online review contexts exceeding the guideline values of CFI $>0.9$ and $\mathrm{RMSEA}<0.07$ and the video sharing context just meeting these guidelines for a model of this complexity (McDonald and Ho 2002).

\section{INSERT TABLE 4 HERE}

Scale reliabilities and convergent validities were replicated across the 3 contexts (see table 4 for summary). Composite reliabilities for all scales are greater than 0.8 and exceed the cutoff value of 0.7. All AVEs are greater than 0.7 and exceed the 0.5 threshold. All item loadings are significant (all loadings $>.60$, with the exception of one item on extraversion $>0.595$ ), and the majority of standardized residuals did not exceed $|2|(\mathrm{SN}=94.421 \%, \mathrm{OR}=92.715 \%, \mathrm{VS}=$ 91.212\%) indicating convergent validity.

Most importantly, discriminant validity was established. The AVEs of all the scales exceeded the associated Squared Interconstruct Correlations (SICs) (Hair et al. 2006). For the 
social networking context, SICs range 0.00004-0.576 and all AVEs exceed 0.7; for the online review context, SICs range 0.0006-0.109 and all AVEs exceed 0.7; for the video sharing context, SICs range 0.0006-0.176 and all AVEs exceed 0.7. The Interconstruct Correlations are presented in table 5. Replicating our previous studies, and underlining its distinctiveness, GOSIP is not significantly correlated with either WtC or extraversion. This further strengthens the case for the need for an online specific concept for social interaction propensity.

Secondly, we found support for our idea that GOSIP is distinct from, but correlated with, both engagement scales. There is a consistently higher within-context correlation between GOSIP and effort engagement, compared to GOSIP and social engagement.

\section{INSERT TABLE 5 HERE}

This demonstrates the general utility of measuring GOSIP to understand subsequent behaviors within different online contexts. In particular, GOSIP is shown consistently to be related to the behavioral component of engagement (effort engagement) in these 3 diverse online interaction contexts (social networks, online reviews and video sharing) that are distinct from the original specific virtual community within which the GOSIP was developed. We find that those high in GOSIP report significantly more behavioral engagement efforts within all 3 of the contexts than those low in GOSIP (see table 6). Similarly, those higher in GOSIP reported a greater sense of social engagement (also table 6).

INSERT TABLE 6 HERE 
Overall, our results indicate that GOSIP is a useful concept for understanding subsequent differences in level of engagement across contexts.

\section{Study 7 - Predictive Validity}

The purpose of Study 7 was to establish the predictive validity of GOSIP in relation to actual online behavior. The information exchange, social interaction and helping behaviors included in Study 5 were all self-reported, and the strong relation between GOSIP and these behaviors might have been influenced by common method variance. Therefore, we administered the GOSIP scale to 162 members of an online technical support community (previously used in Study 5). We then recorded the actual posting behavior of our respondents during a one month period prior to our data collection. We counted the number of posts per respondent and correlated this measure with GOSIP. The correlation was significant and large $(r=.67, p<.001)$, indicating that GOSIP is strongly related to actual online behavior, and not just self-reported behavior.

\section{Study 8 - A Further Test of Predictive Validity}

The results of Study 6 suggested that GOSIP predicts levels of consumer engagement, across three different contexts. Further, our results in Study 7 provided strong support for the predictive validity of the GOSIP scale for actual online interaction behaviors. We chose to replicate Study 7 in a different online context, as Study 7 was carried out in an online technical support community that involves a certain professional element that might introduce a bias. Therefore, we selected a movie community, where members exchange information and opinions on movies and DVDs, which is a pure leisure community that has no professional implications. We posted a thread in the general section and asked members of the community to participate in our research. We also raffled movie vouchers to provide an extrinsic motive to participate. 
Respondents had to provide their community nickname, so that we could trace them and investigate their online behavior. Respondents were informed why we needed their nickname and told they could decide to stop the questionnaire if they did not want us to investigate their online behavior. In total, 40 members of this community participated and provided their nickname (23 male, 17 female).

We then collected objective data by counting how many posts each person had provided in total, as well as during the month preceding the data collection. Furthermore, the community provided us with a statistic called “average number of posts per day” and gives a percentage for each member on how many posts per day have been provided in comparison to all other members. We also collected self-reported data on extraversion (same measurement as in Study 4) and topic salience, measured with a 6-item scale from Srinivasan and Ratchford (1991). We first checked the reliability of GOSIP, topic salience, and extraversion. All three constructs showed a high Cronbach’s alpha (GOSIP $=.92$, topic salience $=.80$, and extraversion $=.85$ ). Furthermore, a factor analysis (using principal axis factoring and varimax rotation) delivered a clean solution with respect to GOSIP. All items of GOSIP loaded significantly on the GOSIP construct and none of the other items from topic salience and extraversion loaded on the GOSIP construct. Due to the limited sample size, we analyzed the relationships between the constructs using Pearson’s correlation.

The results are presented in Table 7. GOSIP is significantly correlated with the objective data of total number of posts $(r=.33, p<.05)$, number of posts in respective period $(r=.41, p<$ $.01)$, and average number of posts per day $(r=.41, p<.01)$. Hence, we confirm that our GOSIP scale is a useful predictor of online posting behavior. Furthermore, GOSIP is significantly positively correlated with topic salience. Obviously, individuals who are genuinely interested in the topic will participate more actively in the community. However, topic salience is neither 
correlated with the number of posts in the period, nor with the average number of posts per day; GOSIP does a better overall job of predicting these behaviors. Underlining the usefulness of the GOSIP concept, extraversion is not significantly related to the online behaviors.

INSERT TABLE 7 HERE

\section{DISCUSSION AND IMPLICATIONS}

In today's profoundly networked marketplace, an extensive line-up of online channels is used by companies to generate and deliver value to their customers. If these online channels are fundamental to the ways in which firms connect to their customers, then we must identify the key tenets that drive value-adding connections. While we acknowledge that media and interactive technology platforms are essential parts of the equation, we posit that organizations also develop an in-depth insight into their customers' interaction preferences and hence consider interactivity as a consumer characteristic. The objective of this research was to develop a better understanding of these individual differences by conceptualizing and developing a measure of general online social interaction propensity (GOSIP). We conceptualize GOSIP as a trait-based individual difference that describes a predisposition of an individual to participate in online interactions and set out to establish a concise operational measure that contributes to furthering a more fundamental understanding of how consumers vary in their engagement in online environments.

We advance an 8-item scale, which demonstrates a replicable unidimensional factor structure, reliability, convergent and discriminant validity, freeness from social desirability bias, and strong nomological and predictive validity. Through an extensive process, we have been able 
to develop a relatively concise scale that satisfies recognized scale development standards and current expectations of major analytical techniques. Importantly, while offline concepts of predispositions to interact show little or no predictive power in the online context, in sharp contrast the GOSIP concept serves as an antecedent that could explain differences in levels of engagement (social and behavioral) and also successfully predicts actual online interaction behaviors (e.g., number of posts). This supports our proposition that an online specific concept of social interaction predisposition is essential, as offline concepts cannot simply be transferred online. Our measure of GOSIP should be of value to both consumer researchers interested in predicting and understanding consumer behavioral differences in online environments, and practitioners as a means of informing the design of efficient strategies for increasing consumer engagement and encouraging a higher volume of online interactions.

\section{Theoretical Implications}

In our research, we have established that online social interaction behavior is driven by general online social interaction propensity - identified as a measurable trait. Accordingly, this could serve as a point of departure for understanding differential patterns of behavior across a multitude of online platforms. For instance, we show that so-called posters of content are generally individuals high in GOSIP, while lurkers are generally low in GOSIP. Also, we demonstrate that GOSIP is related to number of observable online behaviors, including average posts per day, alongside effort and social engagement in diverse online contexts. We provide evidence to support the claim that our focal construct is better equipped to predict online contributions than comparative global and specific personal characteristics, such as willingnessto-communicate and extraversion. 
As online consumer behavior is increasingly taking center stage in academic marketing studies and an array of interesting findings has emerged, we believe that these results could be further explored as well as complemented by taking GOSIP into consideration. In studies that seek to explicate the successful performance of virtual communities, it has been advanced that individual level engagement and participation activity cascades up to community level, thereby adding additional explanatory variance in community performance parameters, such as, contribution activity and recommendation and purchase behaviors (e.g., Algesheimer et al. 2005). Also, future research should further nuance our findings, particularly given the fact that a multichannel environment is often a multi-purpose environment. For example, one could assess how GOSIP interacts with utilitarian or hedonic online motives, or whether there is a more meaningful interaction with intrinsic rather than extrinsic motivation to visit an online platform. Finally, the impact of this predisposition to interact may also be regulated by situational characteristics (e.g., topic of conversation). We need to examine whether such trait-state interactions further aid the prediction of online behavioral engagement.

The conceptualization and measurement of GOSIP should also be of particular use in empirical tests of theories regarding interaction and interactivity functions. Despite a plethora of research on medium interactivity (differences), more research on interaction differences in individuals and the resulting consequences for online social behavior is needed. There is likely to be an interaction between GOSIP and medium interactivity. High GOSIP individuals will probably respond differently to stimuli that solicit online interactivity behavior compared to low GOSIP individuals. While, previous studies have demonstrated that personality has been an important indicator of level of liking of interactive features on Web sites (Nass and Lee 2001), there have been mixed results regarding the relationship between general dispositional concepts (e.g., WtC) and personality (e.g., extraversion) and online behaviors. Some studies find a 
negative relationship, postulating that introverts might be more inclined to communicate online with others (e.g. Amichai-Hamburger et al. 2002). Other studies have also found a nonsignificant relationship (e.g. Peris et al. 2002). We argue that GOSIP, as a specific rather than general measure of predisposition to interact online, offers a credible and valuable alternative to general personality measures. As such, more systematic empirical research may aid our understanding of how interaction and interactivity functions work together.

\section{Managerial Implications}

Similarly, practitioners varying from Web designers to online marketing strategists are expected to benefit from the results of our conceptual and empirical work. Companies and institutions are increasingly trying to deliver value to their customers by engaging them in the marketing process. As interactive technologies reach unprecedented levels of sophistication and an impressive array of online contact points is at the disposal of online marketers, the ability to conduct a two-way dialogue is still at the heart of relational exchanges. The willingness of customers to actively participate and engage in online interactions and communication therefore is now more relevant than ever. Our scale offers managers an actionable instrument that can readily be used to gauge their customers' proneness to interact with their company and assess this in the context of a multi-channel environment and consequently assist in designing effective communication strategies.

Given differential preferences in relation to online interaction and the fact that advances in dynamic Web offering now allow companies to tailor and personalize platforms, it is crucial to take differences between consumers' interaction propensities into account. In line with Kaptein and Eckles (2012), who also find that marketers need to tailor their offerings to individual 
consumer preferences, organizations can identify consumers’ GOSIP and present distinct interaction possibilities. For example, they could offer different after-sales service support channels. Also, as digital content creation is becoming more prevalent in determining a Web site attractiveness and longevity, companies need to understand and nurture their interaction prone users to let them create online content, but be careful not to alienate those with low GOSIP and generate a negative response from this segment. For instance, as more companies allow consumers to actively participate in advertising and promotions by providing personal information and selecting layers of information they receive (i.e., by deciding to click on banners), assessing advertising effectiveness may be strongly correlated with customers' online propensity to interact socially. Likewise, when designing viral content seeding strategies, which may vary from videos to tweets, online marketers may be advised to select consumers who are more likely to interact with their peers to more effectively start up the diffusion process. Finally, when deploying e-recruiting strategies, managers need to be mindful of the fact that in addition to motivations and abilities, applicants may also differ depending on their inclination to react online to a job advertisement. 


\section{REFERENCES}

Algesheimer, Rene, Utpal M. Dholakia, and Andreas Herrmann (2005), "The Social Influence of Brand Community: Evidence from European Car Clubs," Journal of Marketing, 69, 3, 19-34.

Amichai-Hamburger, Yair, Galit Wainapel, and Shaul Fox (2002), "'On the Internet No One Knows I'm an Introvert": Extroversion, Neuroticism, and Internet Interaction," CyberPsychology \& Behavior, 5, 2, 125-128.

Anderson, James C. and David W. Gerbing (1988), "Structural Equation Modeling in Practice: A Review and Recommended Two-Step Approach," Psychological Bulletin, 103, 3, 411-423.

Ariely, Dan (2000), “Controlling the Information Flow: Effects on Consumers' Decision Making and Preferences,” Journal of Consumer Research, 27, 233-48.

Bagozzi, Richard P. (2000), "On the Concept of Intentional Social Action in Consumer Behavior," Journal of Consumer Research, 27, 3, 388-396.

----and Paul R. Warshaw (1990), “Trying to Consume,” Journal of Consumer Research, $17,2,127-40$.

Ballantyne, David, and Richard J. Varey, Richard, (2006), “Creating Value-in-Use through Marketing Interaction: The Exchange Logic of Relating, Communicating and Knowing, Marketing theory,6,3, 335-48.

Brodie, Roderick J., Hollebeek, Linda, D., Juric, Biljana and Ana Ilić (2009), “Customer Engagement: Conceptual Domain, Fundamental Propositions, and Implications for Research,” Journal of Service Research, 14, 3, 252-71. 
Calder, Bobby J. and Edward C. Malthouse (2008), “'Media Engagement and Advertising Effectiveness,'” in Kellogg on Advertising and Media, Bobby J. Calder, ed. Hoboken, NJ: Wiley, $1-36$.

----, ----, and Ute Schaedel (2009), ”An experimental study of the relationship between online engagement and advertising effectiveness,” Journal of Interactive Marketing, 23, 4, 32131.

Comrey, Andrew L., Patrica Noller, and Henry Law (1988), "Eysenck Personality Inventory Item Factor Structure," Multivariate Behavioral Research, 23, 159-170.

Cothrel, Joseph P. and Ruth L. Williams (1999), "On-Line Communities: Helping Them Form and Grow," Journal of Knowledge Management, 3, 1, 54-60.

Cronbach, Lee J. and Paul Meehl (1955), "Construct Validity in Psychological Tests," Psychological Bulletin, 56, March, 81-105.

Crowne, Douglas P. and David Marlowe (1960), "A New Scale for Social Desirability Independent of Psychopathology," Journal of Consulting Psychology, 24, 4, 349-354.

Culnan, Mary J. and M. Lynne Markus (1987), "Information Technologies," in Handbook of Organizational Communication: An Interdisciplinary Perspective, Vol., F. M. Jablin and L. L. Putnam and K. H. Roberts and L. W. Porter, Ed. Newbury Park, CA: Sage.421-443.

Daft, Richard L. and Robert H. Lengel (1986), "Organizational Information Requirements, Media Richness and Structural Design," Management Science, 32, 554-571.

Daniels, David, Matiesanu, Corinna, and David Schatsky, (2003),“Jupiter Consumer Survey Report: The State of Customer Service 2003,” Jupiter Research.

Flaherty, Lisa M., Kevin J. Pearce, and Rebecca B. Rubin (1998), "Internet and Face-toFace Communication: Not Functional Alternatives," Communication Quarterly, 46, 3, 250-268. 
Fornell, Claes and David F. Larcker (1981), "Evaluating Structural Equation Models with Unobservable Variables and Measurement Error,” Journal of Marketing Research, 18, 1, 39-50.

Hair, Joseph F., Black, William C., Babin, Barry J., and Ralph E. Anderson (2006), Multivariate Data Analysis, Prentice Hall.

Hoffman, Donna L. and Thomas P. Novak (1996), “Marketing in Hypermedia Computer Mediated Environments: Conceptual Foundations,” Journal of Marketing, 60, 3, 50-68.

Internet World Statistics (IWS) (2012), http://www.internetworldstats.com/stats.htm accessed on 04 February 2013

Johnson, Grace J., Gordon C. Bruner II, and Anand Kumar (2006), “Interactivity and its Facets Revisited,” Journal of Advertising, 35, 4, 35-52.

Josefsson, Ulrika (2005), "Coping with Illness Online: The Case of Patients' Online Communities," Information Society, 21, 133-53.

Kahn, William A., (1990), "Psychological Conditions of Personal Engagement and Disengagement at Work,” Academy of Management Journal,33, 4, 692-724.

Kammrath, Lara K., Rodolfo Mendoza-Denton, and Walter Mischel (2005), "Incorporating If ... Then ... Personality Signatures in Person Perception: Beyond the PersonSituation Dichotomy," Journal of Personality \& Social Psychology, 88, 4, 605-618.

Kaptein, Maurits and Dean Eckles (2012), "Heterogeneity in the Effects of Online Persuasion,” Journal of Interactive Marketing, 26, 176-88.

Kozinets, Robert V. (1999), "E-Tribalized Marketing?: The Strategic Implications of Virtual Communities of Consumption," European Management Journal, 17.3, 252-264.

----, Kristine de Valck, Andrea C. Wojnicki, and Sarah J.S. Wilner (2010), “Networked Narratives: Understanding Word-of-Mouth Marketing in Online Communities,“Journal of Marketing, 74, 2, 71-89. 
Kumar, V., Aksoy, Lerzan, Donkers, Bas, Venkatesan, Rajkumar, Wiesel, Thorsten and Sebastian Tillmanns (2010), “Undervalued or Overvalued Customers: Capturing Total Customer Engagement Value,” Journal of Service Research, 13, 3, 297-310.

Langelaan, Saar, Bakker, Arnold B., Van Doornen, Lorenz. J., and Wilmar B. Schaufeli, (2006),“Burnout and Work Engagement: Do Individual Differences Make a Difference?” Personality and Individual Differences,40, 3, 521-32.

LePine, Jeffrey A. and Linn Van Dyne (2001), "Voice and Cooperative Behavior as Contrasting Forms of Contextual Performance: Evidence of Differential Relationships with Big Five Personality Characteristics and Cognitive Ability," Journal of Applied Psychology, 86, 2, 326-336.

Libai, Barak, Bolton, Ruth, Bügel, Marnix S., de Ruyter, Ko, Götz, Oliver, Risselada, Hans, and Andrew T. Stephen (2010), “Customer-to-Customer Interactions: Broadening the Scope of Word of Mouth Research,” Journal of Service Research, 13, 3, 267-82.

Liu, Yuping and L.J. Shrum (2002), "What Is Interactivity and Is it Always Such a Good Thing? Implications of Definition, Person, and Situation for the Influence of Interactivity on Advertising Effectiveness,” Journal of Advertising, 31, 4, 53-64.

Macey, William H. and Benjamin Schneider, (2008), “The Meaning of Employee Engagement,“Industrial and Organizational Psychology,1, 1, 3-30.

McCroskey, James C. (1984), “The Communication Apprehension Perspective, “ In J. A. Daly, \& J. C. McCroskey (Eds.), Avoiding communication: Shyness, reticence, and communication, SAGE Publications, Beverly Hills, CA, 13-38.

McCroskey, James C. and Virginia P. Richmond (1990), "Willingness-to-Communicate: A Cognitive View," Journal of Social Behavior and Personality, 5, 19-37. 
McDonald, Roderick P and Ringo Moon-Ho(2002), "Principles and Practice in Reporting Structural Equation Analyses,” Psychological Methods, 7, 1, 64-82.

McKenna, Katelyn Y. A. and John A. Bargh (2000), "Plan 9 from Cyberspace: The Implications of the Internet for Personality and Social Psychology," Personality \& Social Psychology Review, 4, 1, 57-75.

McKenna, Katelyn Y., Green, Amie S., and Marci E. Gleason, (2002), “Relationship Formation on the Internet: What's the Big Attraction?” Journal of Social Issues,58,1, 9-31.

McMillan, Sally J. and Jang-Sun Hwang (2002), “Measures of Perceived Interactivity: An Exploration of the Role of Direction of Communication, User Control, and Time in Shaping Perceptions of Interactivity,” Journal of Advertising, 31, 3, 29-42.

Mehrabian, Albert (1980), Silent Messages: Implicit Communication of Emotions and Attitudes (2nd ed.). Belmont, CA: Wadsworth.

Mollen, Anne and Hugh Wilson (2008), “Engagement, telepresence and interactivity in online consumer experience: Reconciling scholastic and managerial perspectives, ”Journal of Business Research, 63, 9-10, 919-25.

Moon, Youngme (2000), "Intimate Exchanges: Using Computers to Elicit Self-Disclosure from Consumers," Journal of Consumer Research, 26, March, 323-336.

Mortensen, D. C., P. H. Amston, and M. Lustig (1977), "The Measurement of Verbal Predispositions: Scale Development and Application," Human Communication Research, 3, 14658.

Mowen, J. C., and H. Sujan (2005), "Volunteer Behavior: A Hierarchical Model Approach for Investigating Its Trait and Functional Motive Antecedents, “ Journal of Consumer Psychology, 15, 2, 170-82. 
Muñiz Jr., Albert M. and Hope Jensen Schau (2005), "Religiosity in the Abandoned Apple Newton Brand Community," Journal of Consumer Research, 31, 4, 737-747.

PeopleMetrics (2009), “Most Engaged Customers”, accessed at http://www.peoplemetrics.com/wp-content/uploads/2012/06/PeopleMetrics_2009-MostEngaged-Customers-Study_B2C.pdf on April 262013

Peris, R., M.A. Gimeno, D. Pinazo, G. Ortet, V. Carrero, M. Sanchiz, and I. Ibanez (2002), "Online Chat Rooms: Virtual Spaces of Interaction for Socially Oriented People," CyberPsychology\& Behavior, 5, 1, 43-51.

Phillips, Gerald M., (1984), “Reticence: A Perspective on Social Withdrawal,” In J. A. Daly and James C. McCroskey (Eds.), Avoiding communication: Shyness, reticence and communication apprehension, (pp. 51-66). Beverly Hills.

Podsakoff, Philip M., Michael Ahearne, and Scott B. McKenzie (1997), "Organizational Citizenship Behavior and the Quantity and Quality of Work Group Performance," Journal of Applied Psychology, 82, 2, 262-270.

Preece, Jenny, Blair Nonnecke, and Dorine Andrews (2004),“The Top 5 Reasons for Lurking: Improving Community Experiences for Everyone,” Computers in Human Behavior, 20, 2, 201-223.

Reynolds, Kristy E. and Sharon E. Beatty (1999), "Customer Benefits and Company Consequences of Customer-Salesperson Relationships in Retailing," Journal of Retailing, 75, 1, $11-32$.

Ridings, Catherine M., David Gefen, and Bay Arinze (2002), "Some Antecedents and Effects of Trust in Virtual Communities," Journal of Strategic Information Systems, 11, 271-295.

Robinson, Dilys, Sarah Perryman and Sue Hayday, (2004), "The Drivers of Employee Engagement," Report-Institute for Employment Studies. 
Salgueira, Ana, Costa, Patricio, Gonçalves, Mónica Magalhães, Eunice and Manuel Costa, (2012), “Individual Characteristics and Student’s Engagement in Scientific Research: A Cross-Sectional Study,” BMC Medical Education, 12, 1, 95-103.

Salanova, Marisa, Agut, Sonia, and Jose M. Peiro, (2005), “Linking Organizational Resources and Work Engagement to Employee Performance and Customer Loyalty: The Mediation of Service Climate, “ Journal of Applied Psychology,90,6, 1217-27.

Schau, Jensen Hope and Mary C.Gilly (2003), "We Are What We Post?Self-Presentation in Personal Web Space," Journal of Consumer Research, 30, December, 385-404.

----, Muniz Jr, Albert M., and Eric J. Arnould, (2009), “How Brand Community Practices Create Value,“Journal of Marketing,73, 5, 30-51.

Schlosser, Ann E. (2005), "Posting Vs. Lurking: Communicating in a Multiple Audience Context," Journal of Consumer Research, 32, September, 260-265.

Schumann, David W., Andy Artis, and Rachel Rivera (2001), "The Future of Interactive Advertising Viewed through an IMC Lens," Journal of Interactive Advertising, 1, 2, 16-32.

Shoda, Yuichi, Walter Mischel, and Jack C. Wright (1994), "Intraindividual Stability in the Organization and Patterning of Behavior: Incorporating Psychological Situations into the Idiographic Analysis of Personality," Journal of Personality and Social Psychology, 67, 4, 674687.

Smith, Jessi L., Wagaman, Jill, and Ian M. Handley, (2009), “Keeping it Dull or Making it Fun: Task Variation as a Function of Promotion versus Prevention Focus, “ Motivation and Emotion, 33, 2, 150-60.

Song, Ji H. and George M. Zinkhan (2008), “Determinants of Perceived Web Site Interactivity,” Journal of Marketing, 72, 2, 99-113. 
Spiggle, Susan (1994), “Analysis and Interpretation of Qualitative Data in Consumer Research, “ Journal of Consumer Research, 21, 3, 491-503.

Sproull, Lee and Sara Kiesler (1986), "Reducing Social Context Cues: Electronic Mail in Organizational Communication," Management Science, 32, 11, 1492-1512.

Srinivasan, Narasimhan and Brian T. Ratchford (1991), "An Empirical Test of a Model of External Search for Automobiles," Journal of Consumer Research, 18, 2, 263-267.

Steenkamp, Jan-Benedict E.M. and Hans C.M. van Trijp (1991), "The Use of Lisrel in Validating Marketing Constructs," International Journal of Research in Marketing, 8, 4, 283299.

Steuer, Jonathan (1992), “Defining Virtual Reality—Dimensions Determining Telepresence,” Journal of Communication, 42, 4, 73-93.

Tian, Kelly Tepper, William O. Bearden, and Gary L. Hunter (2001), "Consumers' Need for Uniqueness: Scale Development and Validation," Journal of Consumer Research, 28, June, 50-65.

Tremayne, Mark (2005), “Lessons Learned from Experiments with Interactivity on the Web,” Journal of Interactive Advertising, 5, 2, 40-46.

Van Noort, Guda, Voorveld, Hilde A.M., and Eva A. van Reijmersdal (2012), “Interactivity in Brand Web Sites: Cognitive, Affective, and BehavioralResponses Explained by Consumers' Online Flow Experience,” Journal of Interactive Marketing, 26, 223-34.

Valacich, Joseph S., David Paranka, George Joey F., and Jay F. Nunamaker Jr. (1993), "Communication Concurrency and the New Media: A New Dimension for Media Richness," Communication Research, 20,2, 249-276. 
Wiertz, Caroline and Ko de Ruyter (2007), “Beyond the Call of Duty: Why Customers Contribute to Firm-hosted Commercial Online Communities,” Organization Studies, 28, 3, 34776.

Zaichkowsky, Judith Lynne (1994), "The Personal Involvement Inventory: Reduction, Revision, and Application to Advertising," Journal of Advertising, 23, 4, 59-70.

Zakahi, Walter R. and James C. McCroskey (1989), "Willingness-to-Communicate: A Potential Confounding Variable in Communication Research," Communication Reports, 2, 96104.

Zuroff, David C. (1986), "Was Gordon Allport a Trait Theorist?" Journal of Personality and Social Psychology, 51, 5, 993-1000. 


\section{TABLE 1}

\section{Final general online social interaction propensity scale}

Item Wording

In general, I am someone who, given the chance, seeks contact with others online.

In general, I am someone who answers questions of others in online discussion forums.

In general, I am someone who enjoys initiating a dialogue online.

In general, I like to get involved in online discussions.

I find the idea of belonging to an online discussion group pleasant.

I am someone who likes actively participating in online discussions.

I am someone who like interaction with like-minded others online.

In general, I thoroughly enjoy exchanging ideas with other people online.
EFA CFA

$.809 \quad .622$

$.773 \quad .769$

$.751 \quad .678$

$.697 \quad .826$

$.675 \quad .827$

$.632 \quad .707$

$.623 \quad .745$

$.622 \quad .872$

Fit of CFA: Chi square $(\mathrm{df})=30.24(20), \mathrm{NNFI}=.967, \mathrm{CFI}=.976, \mathrm{GFI}=.925, \mathrm{RMSEA}=.058$ 
TABLE 2

Discriminant validity - Study 4

\begin{tabular}{|c|c|c|c|c|c|}
\hline & $\begin{array}{c}\text { Mean } \\
\text { (Std. Dev) }\end{array}$ & $\begin{array}{l}\text { Willingness- } \\
\text { to- } \\
\text { Communicate }\end{array}$ & $\begin{array}{c}\text { Involvement } \\
\text { with online } \\
\text { communication }\end{array}$ & Extraversion & GOSIP \\
\hline $\begin{array}{l}\text { Willingness-to- } \\
\text { Communicate }\end{array}$ & $\begin{array}{c}62.52 \\
(14.49)\end{array}$ & 1.00 & & & \\
\hline $\begin{array}{l}\text { Involvement } \\
\text { with online } \\
\text { communication }\end{array}$ & $\begin{array}{c}4.10 \\
(1.15)\end{array}$ & .014 & 1.00 & & \\
\hline Extraversion & $\begin{array}{c}5.20 \\
(0.72)\end{array}$ & $.248^{*}$ & .014 & 1.00 & \\
\hline GOSIP & $\begin{array}{c}3.22 \\
(1.23)\end{array}$ & .018 & $.609 *$ & .026 & 1.00 \\
\hline
\end{tabular}

* correlation is significant at .05 level 


\section{TABLE 3}

Nomological validity - Study 5

\begin{tabular}{llll} 
Relationship & Beta & t-value & $\mathrm{R}^{2}$ \\
\hline & & & \\
GOSIP $\rightarrow$ information posting behavior & .54 & 5.97 & .29 \\
GOSIP $\rightarrow$ social interaction behavior & .59 & 7.54 & .35 \\
GOSIP $\rightarrow$ helping behavior & .48 & 6.25 & .23 \\
\hline
\end{tabular}

Model Fit: Chisquare $(\mathrm{df})=586.37(167), \mathrm{NNFI}=.90, \mathrm{CFI}=.91, \mathrm{GFI}=.76$, RMSEA $=.086$ 


\section{TABLE 4}

CRs, AVEs, and fit statistics for scales across 3 contexts

\begin{tabular}{|c|c|c|c|c|c|c|}
\hline & & CR & & & AVE & \\
\hline & $\mathrm{SN}$ & OR & VS & $\mathrm{SN}$ & OR & VS \\
\hline GOSIP & 0.934 & 0.934 & 0.934 & 0.796 & 0.795 & 0.796 \\
\hline $\mathrm{WtC}$ & 0.902 & 0.902 & 0.902 & 0.752 & 0.752 & 0.752 \\
\hline Extraversion & 0.871 & 0.871 & 0.871 & 0.725 & 0.725 & 0.725 \\
\hline $\begin{array}{l}\text { Effort } \\
\text { Engagement }\end{array}$ & 0.884 & 0.894 & 0.911 & 0.743 & 0.764 & 0.793 \\
\hline $\begin{array}{l}\text { Social } \\
\text { Engagement }\end{array}$ & 0.827 & 0.827 & 0.824 & 0.781 & 0.781 & 0.779 \\
\hline $\begin{array}{l}\text { Fit statistics } \\
\text { CMIN } \\
(\text { d.f. = 395) }\end{array}$ & $867.499 * * *$ & 799.619*** & $973.877 * * *$ & & & \\
\hline CMIN/df & 2.196 & 2.024 & 2.466 & & & \\
\hline GFI & 0.830 & 0.843 & 0.802 & & & \\
\hline NNFI (TLI) & 0.919 & 0.903 & 0.884 & & & \\
\hline CFI & 0.912 & 0.926 & 0.894 & & & \\
\hline $\begin{array}{l}\text { RMSEA } \\
(90 \% \text { CI) }\end{array}$ & $\begin{array}{l}0.064 \\
(0.058- \\
0.070) \\
\end{array}$ & $\begin{array}{l}0.059 \\
(0.053- \\
0.065) \\
\end{array}$ & $\begin{array}{l}0.071 \\
(0.065- \\
0.077) \\
\end{array}$ & & & \\
\hline
\end{tabular}

$\mathrm{SN}=$ Social networking, $\mathrm{OR}=$ Online reviews, VS= Video sharing; ${ }^{* * *} \mathrm{p}<0.001$ 
TABLE 5

Interconstruct correlations for 3 contexts

\begin{tabular}{|l|l|l|r|r|r|}
\hline & & & $\begin{array}{r}\text { SN } \\
\text { Estimate }\end{array}$ & $\begin{array}{r}\text { OR } \\
\text { Estimate }\end{array}$ & $\begin{array}{r}\text { VS } \\
\text { Estimate }\end{array}$ \\
\hline GOSIP & $<-->$ & WtC & .025 & .024 & .024 \\
\hline GOSIP & $<-->$ & Extraversion & .221 & .220 & .221 \\
\hline GOSIP & $<-->$ & Effortengagement & $.565^{* * *}$ & $.330^{* * *}$ & $.420^{* * *}$ \\
\hline GOSIP & $<-->$ & Social engagement & $.535^{* * *}$ & $.245^{* * *}$ & $.272^{* * *}$ \\
\hline Effortengagement & $<-->$ & WtC & -.006 & -.136 & -.131 \\
\hline Effort engagement & $<-->$ & Extraversion & $.407 * * *$ & .232 & $.261^{* * *}$ \\
\hline Effort engagement & $<-->$ & Social engagement & $.759^{* * *}$ & $.241^{* * *}$ & $.530^{* * *}$ \\
\hline Social engagement & $<-->$ & WtC & .077 & .051 & -.125 \\
\hline Social engagement & $<-->$ & Extraversion & $.290^{* * *}$ & .073 & .212 \\
\hline Extraversion & $<-->$ & WtC & .185 & .184 & .185 \\
\hline
\end{tabular}

$* * * \mathrm{p}<0.001$ 
TABLE 6

GOSIP group differences in effort and social engagement (scale 1-7) across contexts

\begin{tabular}{|c|c|c|c|c|c|c|c|}
\hline \multicolumn{8}{|c|}{ Effort Engagement } \\
\hline & $\begin{array}{l}\text { Very low } \\
\text { GOSIP } \\
\text { (-2 s.d.s) }\end{array}$ & $\begin{array}{l}\text { Low } \\
\text { GOSIP } \\
\text { (-1 s.d.) }\end{array}$ & Neutral & $\begin{array}{l}\text { High } \\
\text { GOSIP } \\
\text { (+1 s.d.) }\end{array}$ & $\begin{array}{l}\text { Very } \\
\text { High } \\
\text { GOSIP } \\
\text { (+2 s.d.s) }\end{array}$ & $\begin{array}{l}\text { Total } \\
\text { (s.d.) }\end{array}$ & F (d.f.) \\
\hline $\begin{array}{l}\text { Social } \\
\text { Network }\end{array}$ & 2.33 & 2.43 & 3.22 & 3.89 & 4.70 & $\begin{array}{l}3.52 \\
(1.47)\end{array}$ & $\begin{array}{l}20.77^{* * *} \\
\text { (4) }\end{array}$ \\
\hline $\begin{array}{l}\text { Online } \\
\text { Review }\end{array}$ & 1.19 & 1.47 & 2.19 & 2.48 & 2.45 & $\begin{array}{l}2.20 \\
(1.26) \\
\end{array}$ & $\begin{array}{l}7.58^{* * *} \\
(4)\end{array}$ \\
\hline $\begin{array}{l}\text { Video } \\
\text { Sharing }\end{array}$ & 1.61 & 1.44 & 2.11 & 2.72 & 3.19 & $\begin{array}{l}2.38 \\
(1.39)\end{array}$ & $\begin{array}{l}13.26^{* * *} \\
(4)\end{array}$ \\
\hline \multicolumn{8}{|c|}{ Social Engagement } \\
\hline $\begin{array}{l}\text { Social } \\
\text { Network }\end{array}$ & 2.78 & 3.52 & 3.94 & 4.81 & 5.86 & $\begin{array}{l}4.43 \\
(1.51)\end{array}$ & $\begin{array}{l}25.31 * * * \\
\text { (4) }\end{array}$ \\
\hline $\begin{array}{l}\text { Online } \\
\text { Review }\end{array}$ & 3.15 & 3.65 & 4.19 & 4.64 & 4.99 & $\begin{array}{l}4.35 \\
(1.53)\end{array}$ & $\begin{array}{l}7.13^{* * * *} \\
(4)\end{array}$ \\
\hline $\begin{array}{l}\text { Video } \\
\text { Sharing }\end{array}$ & 2.67 & 2.91 & 3.35 & 3.95 & 4.32 & $\begin{array}{l}3.63 \\
(1.74)\end{array}$ & $\begin{array}{l}5.94 * * * \\
\text { (4) }\end{array}$ \\
\hline
\end{tabular}


TABLE 7

Correlations between GOSIP and objective data

\begin{tabular}{|c|c|c|c|c|c|c|c|}
\hline & $\begin{array}{c}\text { Mean } \\
\text { (Std. Dev) }\end{array}$ & GOSIP & TS & EXT & TNP & NPP & AVP \\
\hline GOSIP & $\begin{array}{l}5.05 \\
(1.10)\end{array}$ & 1.00 & & & & & \\
\hline $\begin{array}{l}\text { Topic salience } \\
\text { (TS) }\end{array}$ & $\begin{array}{l}6.37 \\
(.60)\end{array}$ & $.52^{* *}$ & 1.00 & & & & \\
\hline $\begin{array}{l}\text { Extraversion } \\
(\mathrm{EXT})\end{array}$ & $\begin{array}{l}4.88 \\
(.90)\end{array}$ & -.08 & -.01 & 1.00 & & & \\
\hline $\begin{array}{l}\text { Total number of } \\
\text { posts (TNP) }\end{array}$ & $\begin{array}{c}2412.43 \\
(2812.67)\end{array}$ & $.33^{*}$ & $.34^{*}$ & -.10 & 1.00 & & \\
\hline $\begin{array}{l}\text { Number of posts } \\
\text { in period (NPP) }\end{array}$ & $\begin{array}{l}109.08 \\
(110.0)\end{array}$ & $.41^{* *}$ & .14 & -.03 & $.69^{* *}$ & 1.00 & \\
\hline $\begin{array}{l}\text { Average per day } \\
(\mathrm{AVP})\end{array}$ & $\begin{array}{c}3.03 \\
(2.76) \\
\end{array}$ & $.41^{* *}$ & .26 & -.21 & $.67^{* *}$ & $.76^{* *}$ & 1.00 \\
\hline
\end{tabular}


Figure 1: Emergent themes for GOSIP

- Contribute

- Initiation/Start up a chat

- Provision/Guidance/ Helping out

- Receiving/Consult

- Active in seeking contact with others

- Being involved /Participating

- Sense of belonging/ Likeminded individuals/Feels like home

- Likes to actively participate

- Enjoys exchange with others

- Likes chatting

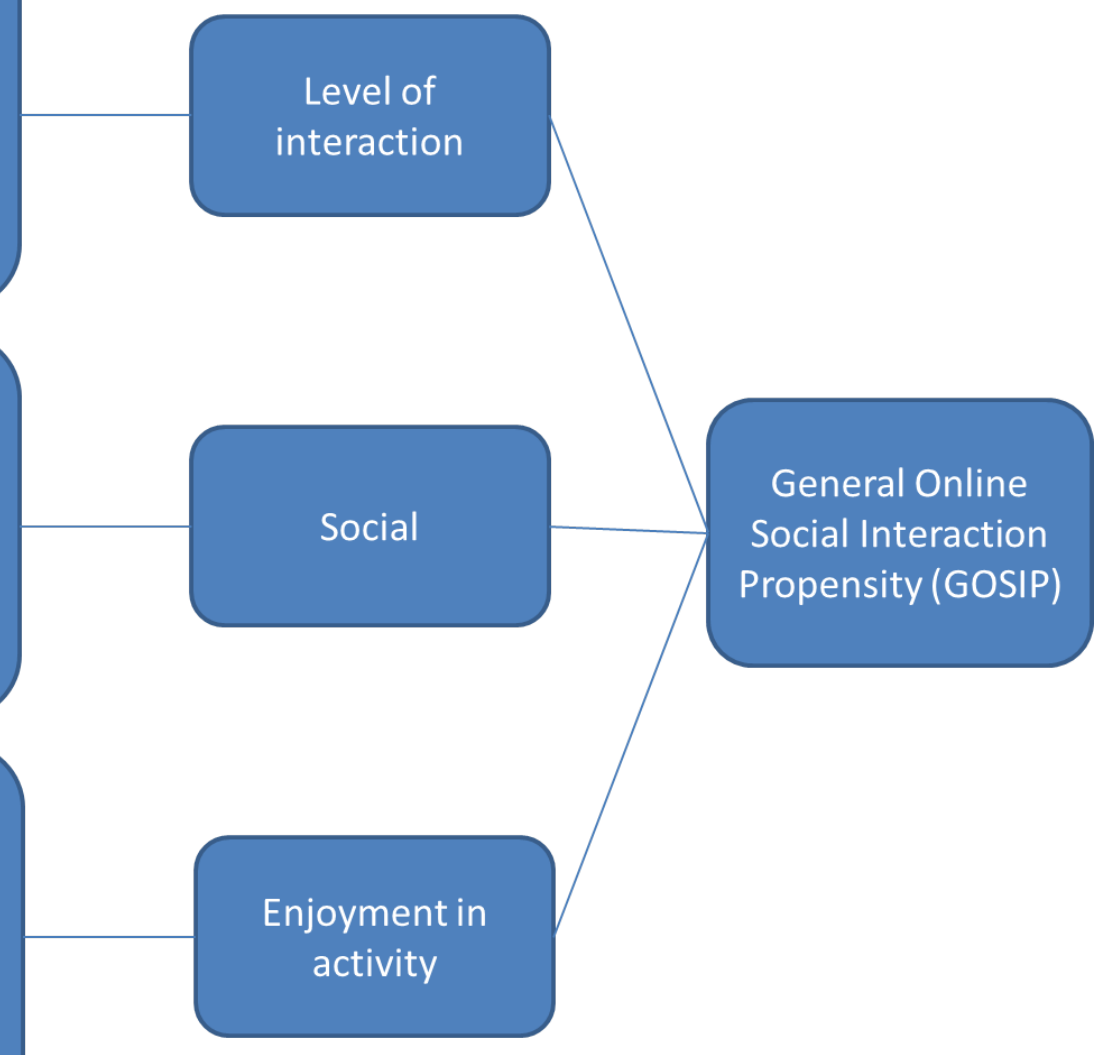

